

\title{
Neoconservadurismo versus populismo socialdemócrata. Una comparación de los discursos anticorrupción de Iván Duque y Gustavo Petro en la segunda vuelta presidencial de $2018^{*}$
}

\author{
Blendi Kajsiu (Albania)** \\ Yenifer Tamayo Grisales (Colombia)***
}

\section{Resumen}

El argumento central de este artículo es que los discursos anticorrupción de los entonces candidatos presidenciales Iván Duque y Gustavo Petro durante la campaña electoral de 2018 reflejan sus respectivas ideologías: neoconservadurismo y populismo socialdemócrata, respectivamente. Se analizan los discursos durante la campaña presidencial de 2018, combinando el análisis conceptual de las ideologías desarrollado por Michael Freeden y el maco teórico de análisis discursivo de Ernesto Laclau y Chantal Mouffe. A diferencia de la gran mayoría de trabajos sobre la corrupción en Colombia esta investigación no se enfoca en evaluar las propuestas anticorrupción sino en desentrañar sus presupuestos ideológicos. Se encontró que, desde la perspectiva neoconservadora, Duque identifica la corrupción principalmente en el sector público y su propuesta anticorrupción se limita a reformar el Estado, sin cambiar las estructuras socioeconómicas del país; el discurso anticorrupción de Petro refleja su populismo socialdemócrata, donde la corrupción emerge como característica de la clase política y de un sistema socioeconómico altamente desigual en general, cuya eliminación implica la transformación de las estructuras políticas, sociales y económicas de Colombia.

\section{Palabras clave}

Política Electoral; Comunicación Política; Discurso Político; Ideologías Políticas; Política Comparada.

\footnotetext{
* Este artículo es producto del proyecto de investigación de Un análisis Crítico de los Discursos Anticorrupción en Colombia, 1990-2016, financiado por el Fondo de Apoyo al Primer Proyecto, Universidad de Antioquia.

** Politólogo y economista. Magíster en Estudios Internacionales de Paz. Magíster y doctorado en Análisis de Ideología y Discurso. Facultad de Derecho y Ciencias Políticas, Universidad de Antioquia UdeA. Calle 70 No. 52-21, Medellín, Colombia. Correo electrónico: blendi.kajsiu@udea.edu.co Google Scholar: https://scholar.google.es/citations?user=4FW5MPYAAAAJ\&hl=es

*** Facultad de Derecho y Ciencias Políticas, Universidad de Antioquia UdeA. Calle 70 No. 52-21, Medellín, Colombia. Correo electrónico: yenifer.tamayog@udea.edu.co
} 
Fecha de recepción: enero de 2019 • Fecha de aprobación: junio de 2019

Cómo citar este artículo

Kajsiu, Blendi y Tamayo Grisales, Yenifer. (2019). Neoconservadurismo versus populismo socialdemócrata. Una comparación de los discursos anticorrupción de Iván Duque y Gustavo Petro en la segunda vuelta presidencial de 2018. Estudios Políticos (Universidad de Antioquia), 56, pp. 123-147. DOI: 10.17533/udea.espo.n56a06

\title{
Neoconservatism Versus Social Democrat Populism. A Comparison of Anti-Corruption Speeches by Ivan Duque and Gustavo Petro in the Second Round of the 2018 Presidential Election
}

\begin{abstract}
The main argument of this article is that the anticorruption discourses of the 2018 presidential candidates, Ivan Duque and Gustavo Petro, reflect their ideologies, namely, neoconservatism and populist-social democracy, respectively. Their speeches during the 2018 election campaign are analyzed combining the conceptual

[124 ] analysis of ideologies developed by Michael Freeden and the theoretical framework of discourse analysis developed by Ernesto Laclau and Chantal Mouffe. Unlike the vast majority of research on corruption in Colombia, this investigation does not focus on evaluating the anticorruption proposals, but rather on unveiling their ideological assumptions. It was found that from his neoconservative perspective, Duque locates corruption principally in the public sector, and therefore, his anticorruption policy proposal was limited to reforming the State, without touching the existing socioeconomic structures in the country. Petro's anticorruption discourse, on the other hand, reflects his social democratic populism according to which corruption is a characteristic of both the ruling political class and a highly unequal socio-economic system; therefore, the elimination of corruption calls for the transformations of the social, economic and political structures of Colombia.
\end{abstract}

\section{Keywords}

Electoral Politics; Political Communication; Political Speech; Political Ideologies; Comparative Politics. 


\section{Introducción. La dimensión ideológica del concepto corrupción}

Aunque a menudo se habla de la corrupción como si fuera un fenómeno claro o un objeto bien delimitado, es importante enfatizar que el concepto es esencialmente ideológico. La definición de corrupción siempre ocurre en relación con ciertos ideales económicos, políticos o sociales. Según Mark Philp (1997, p. 446), la concepción de la corrupción política «está arraigada en modos de pensar sobre la política, es decir, que exista alguna "condición naturalmente sana» (descrita de manera diferente por diferentes autores) de la cual un acto corrupto se desvía». 'Esto implica que la definición de la corrupción refleja ciertos ideales políticos en particular y el entendimiento de la política en general y, por eso, no puede existir un consenso sobre la naturaleza de este fenómeno (Philp y David-Barret, 2015 , p. 392). Si un ideal político es la justicia social, entonces la corrupción se define como injusticia social, pero si el ideal es la competencia libre entonces representa la falta o la distorsión de esta.

Esto es de suma importancia porque mientras no hay un consenso sobre la naturaleza de la corrupción, sí existe unanimidad sobre la necesidad de erradicarla. Esta unanimidad se puede utilizar fácilmente para legitimar e implementar sigilosamente una agenda o ideología política bajo la bandera de la anticorrupción. Resulta mucho más conveniente defender o implementar cierto ideal político como una cura contra la corrupción que justificarlo de manera explícita por sus propios méritos a través del debate público. Es más fácil, por ejemplo, justificar la reducción del gasto público o un Estado austero como medidas que acotan la corrupción pública, que como políticas que mejoran la economía o la sociedad.

Dada la importancia del aspecto ideológico de la corrupción es sorprendente la escasa atención que ha recibido en la ciencia política en general y en Colombia en particular. De un sinnúmero de artículos, investigaciones y libros sobre la corrupción solamente se pudo encontrar dos artículos que abordaran su dimensión ideológica (Montoya, 2000; Vásquez y Montoya, 2011). Con la investigación que nutre este artículo se contribuye a llenar dicho vacío, mostrando que la lucha contra la corrupción refleja y sirve para articular diferentes ideologías políticas.

${ }^{1}$ Traducción propia desde el original. 
Al comparar los discursos anticorrupción de los candidatos Iván Duque y Gustavo Petro en las elecciones presidenciales de 2018 en Colombia, se muestra que el candidato uribista, Iván Duque, representa un proyecto político neoconservador que combina el enfoque conservador de mantener el statu quo por medio de la restauración de la legalidad, la institucionalidad y la autoridad con conceptos básicos del neoliberalismo, como la competencia y el mercado libre, como fuentes principales del desarrollo socioeconómico. Por esta razón, ubica la corrupción principalmente en el sector público y mucho menos en el sector privado, y su propuesta anticorrupción se limita a la reforma del Estado y no de las estructuras socioeconómicas del país.

Por su parte, el discurso anticorrupción de Petro combina una ideología populista que se centra en el antagonismo pueblo-élite con conceptos centrales de la socialdemocracia que, por un lado, reconoce el mercado como fuente de desarrollo, pero al mismo tiempo resalta la importancia de la justicia social, la igualdad y del trabajo como valores fundamentales. Por consiguiente, en el discurso petrista la corrupción emerge como característica de la clase política y del sistema socioeconómico en general, cuya eliminación implica la transformación de la estructura política, social y económica de Colombia.

Para desarrollar el argumento anterior, se combina el análisis de discurso de Ernesto Laclau y Chantal Mouffe con el análisis conceptual de la ideología desarrollado por Michael Freeden, se caracteriza la ideología neoconservadora de Ivan Duque y el populismo socialdemócrata del petrismo, y se muestra cómo estas distintas ideologías producen dos diferentes discursos anticorrupción.

\section{Marco teórico y metodológico: el análisis discursivo e ideológico de la corrupción}

Desde una perspectiva discursiva, la corrupción no es un fenómeno que sostiene una esencia inalterable, identificable a través de diferentes contextos. Esto supone que en lugar de analizar la corrupción como un concepto que tiene un contenido fijo, es mejor tratarlo como un signo que tiene un significante y un significado. El significante es la imagen acústica del signo, mientras que el significado es su contenido (Howarth, 2000, p. 19). La corrupción como signo consiste en el significante «corrupción», que es la 
imagen y el sonido de esta palabra, y el significado que es el contenido del concepto «corrupción» - soborno, cohecho, peculado, concusión, abuso del poder, desfalco, nepotismo, inmoralidad, degradación, entre otros-. De esta manera, en lugar de buscar el denominador común de sus diferentes definiciones, es mejor mostrar cómo el significante «corrupción» asume diferentes significados dentro de distintos discursos.

El concepto de significante flotante - floating signifier - desarrollado por Laclau y Mouffe (1984) es muy útil para identificar este proceso. Según ellos, el significante flotante se caracteriza por el «deslizamiento del significado bajo el significante» (Torfing, 2004, p. 62). Especialmente en los regímenes democráticos, la contienda política se concentra en enlazar significantes como democracia, libertad o igualdad con significados específicos. La manera como esto sucede es un reflejo de la agenda y perspectiva política de cada actor. Por ejemplo, algunos discursos de la izquierda pueden conectar el significante corrupción con significados como especulación financiera, fraude al consumidor o captura del Estado por intereses privados, los cuales ubican la corrupción principalmente en el sector privado. Los discursos de la derecha conservadora, por otro parte, pueden vincular el mismo significante con significados como ilegalidad o falta de respeto por la autoridad y la ley.

Cuando un significante flotante empieza a asumir un sinfín de significados pierde su significado específico y se transforma en un significante vacío. La manera más sencilla de describirlo es como un significante sin significado (Torfing, 2004, p. 301). A través de los significantes vacíos, una demanda particular, sin abandonar su particularidad completamente, se transforma en un significante que representa un amplio abanico de demandas. El concepto de anticorrupción, por ejemplo, se puede transformar en un significante vacío que crea una "cadena de equivalencia» (Laclau, 2005, p. 39) entre varias demandas que de otra manera serían contradictorias. En contra de la corrupción se podría abogar por más intervención estatal para combatirla y, al mismo tiempo, limitación de la intervención estatal para reducir la corrupción pública.

En este punto es importante observar que el proceso de significación a través de la relación dinámica entre significantes — flotantes y vacíos- y sus significados es en esencia un proceso ideológico. Según Freeden (2013, p. 75), fijar el significado de un concepto es una de las funciones principales 
de la ideología. Desde su perspectiva, una «ideología es una organización estructural de amplia pretensión que atribuye significados despolemizados a una serie de conceptos políticos que se definen entre sí mutuamente». Bajo dicha lógica, las ideologías «están caracterizadas por una morfología que exhibe conceptos centrales, adyacentes y periféricos» (Freeden, 1996, p. 78). Los conceptos centrales constituyen el núcleo conceptual de una ideología que se puede identificar en todas sus diferentes manifestaciones históricas.

Por ejemplo, existen por lo menos dos grandes corrientes históricas del neoliberalismo, «la corriente del ordoliberalismo alemán, representada principalmente por W. Eucken y W. Ropke, y la corriente austronorteamericana, representada por Ludwig von Mises y Friedrich Hayek» (Laval y Dardot, 2010, p. 24). Mientras que los segundos proponen la reducción del Estado y la expansión del mercado, los primeros defienden la intervención estatal en la economía. Sin embargo, a pesar de sus diferencias sobre el rol del Estado en la economía, ambas versiones comparten la misma racionalidad básica, que es «la generalización de la competencia como norma de conducta y de la empresa como modelo de subjetivación» (Laval y Dardot, 2010, p. 15). En ambas versiones, el mercado y la competencia son las fuentes principales del desarrollo socioeconómico y, por lo tanto, el Estado debería actuar en función del mercado. En palabras de Michel Foucault (2007, pp. 148), «un Estado bajo la vigilancia del mercado más que un mercado bajo la vigilancia del Estado». A diferencia del liberalismo clásico, en la ideología neoliberal el mercado no representa solamente un espacio de libertad, sino que constituye un orden de relaciones económicas «que están en el fundamento del vínculo social» (Laval y Dardot, 2010, p. 163). En este sentido, el mercado, la competencia y el emprendimiento son conceptos centrales del neoliberalismo. La responsabilidad personal es también un corolario central de la ideología neoliberal, dentro de la cual: "Cada individuo es responsable y debe responder por sus acciones y su bienestar» (Harvey, 2007, p. 75). Es un concepto estrechamente relacionado con el ideal del mercado y de la competencia. Claramente, en un mercado y competencia libre los actores son los únicos responsables de su éxito o fracaso.

De igual forma, existen varios tipos de conservadurismo, no obstante, todos comparten un supuesto básico: «el orden social está fundado en leyes que no se hallan sometidas al control humano» (Freeden, 2013, p. 111). 
Las leyes del mercado o de la evolución biológica, por ejemplo, no son producto de la voluntad o de la inteligencia humana. Cualquier cambio que contradice o interfiere con estas leyes es «antinatural» y está destinado a producir consecuencias negativas en la sociedad. Por esta razón, según los conservadores, la ingeniería social produce resultados catastróficos como muestran las diferentes revoluciones políticas —-francesa, rusa o cubana-, dado que intentan someter las leyes sociales a la voluntad y al conocimiento humano limitado. Por lo tanto, hay que respetar y mantener el statu quo y mejorarlo de manera paulatina y no radical. A menudo esto conlleva la «racionalización de las instituciones existentes en términos de Dios, naturaleza u hombre» (Huntington, 1957, p. 457). Lo que no quiere decir que el orden social no se pueda mejorar, sino que se puede hacer solamente a través de un «cambio social que se percibe como orgánico, natural y gradual» (Freeden, 1996, p. 409). Por lo tanto, la ideología conservadora valora la tradición e instituciones tradicionales —como la familia, la religión, entre otros-, el orden, la autoridad y el respeto para la ley —o la legalidad-. Son todos conceptos centrales del conservadurismo que suponen la protección y el mantenimiento del statu quo.

También existen varias expresiones del populismo en la izquierda y la derecha; no obstante, todos comparten unos pocos conceptos centrales como el antagonismo entre un pueblo honesto y una élite corrupta, y el pueblo como la única fuente de legitimidad política — soberanía popular(Stanley, 2008, p. 102). Estos conceptos, que se encuentran en las diferentes manifestaciones geográficas e históricas del populismo, constituyen su núcleo central, pero no solamente por esto pertenecen a dicho núcleo, sino porque son «conceptos claves ineludibles que se manifiestan en el uso político práctico» (Freeden, 2013, p. 83), es decir, son los conceptos más importantes de una ideología.

Finalmente, la democracia social pertenece a la familia ideológica del socialismo. En este sentido, comparte algunos de los conceptos y características centrales de dicha ideología, como el énfasis sobre la igualdad, justicia social, trabajo y solidaridad. Según Andrew Heywood (2017, p. 95), «el valor central, y algunos dirían definitivo, del socialismo es la igualdad, especialmente la igualdad social». Otros valores socialistas como la importancia del trabajo humano, el progreso social y la solidaridad también hacen parte de la ideología socialdemócrata. Según Freeden (2013, 
p. 107), el socialismo «prioriza el trabajo (también Ilamado fuerza de trabajo, creatividad, productividad o actividad) como el rasgo constitutivo fundamental de la naturaleza humana y en consecuencia como el elemento básico alrededor del cual ha de estructurarse la organización social». La socialdemocracia comparte este énfasis sobre el valor del trabajo como fuente del desarrollo personal y social. No es ninguna coincidencia que el partido más grande e importante socialdemócrata del Reino Unido se llame Labour Party —Partido del Trabajo-.

Sin embargo, a diferencia de los socialistas y comunistas, los socialdemócratas no proponen superar o derrocar el capitalismo a través de una revolución social, sino su humanización «a través de la reducción de las desigualdades materiales y la pobreza» (Heywood, 2017, p. 95). A pesar de sus varias transformaciones, la socialdemocracia articula y prioriza unos conceptos básicos que los distinguen de otras ideologías. Los más importantes son la igualdad, justicia social, solidaridad y trabajo. Naturalmente, estos conceptos centrales se articulan con otros adyacentes como la aceptación del mercado libre como fuente de desarrollo, lo cual diferencia a la socialdemocracia del socialismo.

[130] Los conceptos centrales se definen entre ellos y en relación con los conceptos adyacentes que limitan su sentido dentro de un contexto lógico o cultural. Por ejemplo, el concepto central del populismo, el antagonismo pueblo-élite, en América Latina se conecta a menudo con el antiimperialismo o el anticolonialismo por razones históricas y culturales. Por las mismas razones, en los países europeos este mismo concepto central se conecta con el nacionalismo, el antisemitismo o el antiislamismo (Kajsiu, 2017, p. 215). A saber, conceptos como antiimperialismo, nacionalismo o xenofobia no son conceptos centrales del populismo porque no se encuentran en todas sus expresiones históricas.

A diferencia de los conceptos adyacentes, los periféricos se «encuentran situados en el perímetro exterior de una ideología, entre el pensamiento y la acción» (Freeden, 2013, p. 84), en este punto los conceptos pierden su abstracción y «se entretejen con las prácticas concretas sancionadas o rechazadas por una ideología». En otros términos, los conceptos periféricos son las prácticas o políticas públicas que produce cierta ideología en un contexto concreto. 


\subsection{Implicaciones metodológicas}

La perspectiva discursiva de Laclau y Mouffe y el marco teórico de Freeden resultan útiles para identificar los conceptos centrales de las ideologías de Duque y Petro, además de cómo estos se articulan con el concepto de corrupción para producir distintos discursos y propuestas anticorrupción. A tal fin, se desarrolló un análisis cuantitativo y cualitativo de los discursos de ambos candidatos que mencionan la corrupción al menos una vez. ${ }^{2}$ Acerca de la selección de los discursos, en el caso de Petro, se tomaron aquellos de su campaña presidencial entre los meses de febrero y junio de 2018. Con Duque, se tomaron los discursos de su campaña y precampaña presidencial entre julio de 2017 y junio de 2018. Esto tuvo el propósito de que el número de menciones de la corrupción fuera lo más similar posible entre ambos (véase tabla 1).

Tabla 1. Discursos de los candidatos a la Presidencia de Colombia en 2018.

\begin{tabular}{|l|c|c|c|c|c|}
\hline \multicolumn{1}{|c|}{ Candidato } & $\begin{array}{c}\text { Total de } \\
\text { discursos }\end{array}$ & $\begin{array}{c}\text { Menciones totales de } \\
\text { la corrupción }\end{array}$ & $\begin{array}{c}\text { Menciones } \\
\text { analizadas }\end{array}$ & $\begin{array}{c}\text { Total de } \\
\text { palabras }\end{array}$ & Años \\
\hline Iván Duque & 84 & 224 & 123 & 108130 & $2017-2018$ \\
\hline Gustavo Petro & 40 & 271 & 136 & 342564 & 2018 \\
\hline
\end{tabular}

Fuente: elaboración propia.

Primero, se hizo un análisis de contenido de los discursos identificando la frecuencia de los conceptos básicos de las cuatro ideologías expuestas en el apartado anterior; segundo, se evaluaron cuantitativamente la frecuencia con que los aspirantes identificaban la corrupción como un rasgo inherente al sector público, al sector privado, a la interacción entre los dos sectores público-privado- o como un fenómeno sociocultural que abarca la cultura, el sistema político, económico y social en su totalidad. Para ello se realizó la siguiente codificación del uso de este concepto (véase cuadro 1).

\footnotetext{
${ }^{2}$ Los discursos de Duque se descargaron de su página oficial en época de campaña (http://www. ivanduque.com/) en la sección de prensa. Con Petro la situación fue diferente, porque no se encontró un sitio donde estuvieran recopilados todas sus declaraciones, por lo cual se recurrió a los vídeos de sus discursos de campaña subidos en diferentes canales de YouTube. Lamentablemente, muchos de las fuentes consultadas ya no están disponibles, no obstante, los autores tienen un archivo propio con todo el material de soporte.
} 
Cuadro 1. Categorías de articulación de la corrupción.

\begin{tabular}{|l|l|}
\hline \multicolumn{1}{|c|}{ Categoría } & \multicolumn{1}{|c|}{ Descripción } \\
\hline $\begin{array}{l}\text { Corrupción } \\
\text { pública }\end{array}$ & $\begin{array}{l}\text { Fenómeno perteneciente exclusivamente al sector público. Incluye } \\
\text { el Estado, las instituciones, los políticos, los servicios públicos como } \\
\text { educación, salud, policía, autoridades fiscales, empresas públicas, } \\
\text { entre otros; también fenómenos como maquinarias y clientelismo } \\
\text { político. }\end{array}$ \\
\hline $\begin{array}{l}\text { Corrupción } \\
\text { privada }\end{array}$ & $\begin{array}{l}\text { Incluye el abuso del poder en el mercado por parte, por ejemplo, de } \\
\text { firmas privadas que utilizan su posición monopólica u oligopólica. } \\
\text { Incluye la corrupción en los negocios, asociaciones de sociedades } \\
\text { como ONG, los medios de comunicación y las fundaciones privadas; } \\
\text { también incluye fenómenos como evasión de impuestos, especulación } \\
\text { financiera o fraude al consumidor. }\end{array}$ \\
\hline $\begin{array}{l}\text { Corrupción } \\
\text { público-privada }\end{array}$ & $\begin{array}{l}\text { Corrupción como resultado de la interacción entre el sector público y } \\
\text { el sector privado. Incluye fenómenos como la contratación pública, la } \\
\text { financiación de campañas políticas por parte de privados y la captura } \\
\text { del Estado por intereses privados. }\end{array}$ \\
\hline $\begin{array}{l}\text { Corrupción } \\
\text { sociocultural }\end{array}$ & $\begin{array}{l}\text { Corrupción como un fenómeno social, cultural, moral o ético. } \\
\text { Incluye fenómenos como la falta de cultura de legalidad, falta de } \\
\text { ética e integridad personal, entre otros. También como un fenómeno } \\
\text { que involucra a los sectores privado y público, y a la sociedad en } \\
\text { general; también incluye fenómenos como el narcotráfico, la captura } \\
\text { de la política y la economía dominada por minorías. }\end{array}$ \\
\hline Otros & $\begin{array}{l}\text { Corrupción como un fenómeno que no se adscribe a ninguna de las } \\
\text { categorías mencionadas. }\end{array}$ \\
\hline
\end{tabular}

Fuente: elaboración propia a partir de Kajsiu (2018, p. 305).

Del total de las menciones sobre la corrupción en los discursos de Duque y Petro, 224 y 271 respectivamente, se eligió una muestra aleatoria representativa: 123 para Duque y 136 para Petro. Se analizaron tales menciones dentro de su respectivo párrafo, determinando la categoría a la que pertenecen; finalmente, se desarrolló un análisis cualitativo que muestra cómo las ideologías de cada candidato moldean su discurso anticorrupción.

\section{El neoconservadurismo de Duque versus el populismo socialdemócrata de Petro}

Para perfilar y comparar los rasgos ideológicos de Duque y Petro, a parte de los conceptos centrales de las cuatro ideologías - conservadurismo, neoliberalismo, populismo y socialdemocracia- identificados en el marco teórico, se introdujeron otros conceptos proxy —o sustitutitos-que permiten evaluar posturas que no se pueden medir directamente. Por ejemplo, es 
difícil medir directamente la crítica de la ideología neoliberal al Estado y su intervención en la economía, por lo tanto, se utilizó el concepto de burocracia, a través del cual se expresa dicha crítica. En este sentido, la burocracia es un concepto proxy en cuanto representa o sustituye la crítica del Estado y su intervención en la economía. En cada caso se dividió el número de veces que el concepto aparece en el discurso por la totalidad de las palabras y se multiplicó por 1000 (véase tabla 2).

Tabla 2. Frecuencia de conceptos ideológicos en los discursos de Duque y Petro, 2017-2018.

\begin{tabular}{|c|c|c|c|}
\hline \multirow{2}{*}{ Ideología } & \multirow{2}{*}{ Concepto } & \multicolumn{2}{|c|}{ Discurso } \\
\hline & & Duque & Petro \\
\hline \multirow[t]{3}{*}{ Populismo } & Pueblo $^{3}$ & 0,47 & 1,61 \\
\hline & Oligarquía & 0 & 0,15 \\
\hline & Clase política & 0,02 & 0,35 \\
\hline \multirow[t]{6}{*}{ Conservadurismo } & Orden & 0,15 & 0,06 \\
\hline & Autoridad & 0,29 & 0,09 \\
\hline & Tradición/Tradicional & 0,06 & 0,03 \\
\hline & Institución/Institucionalidad & 0,80 & 0,13 \\
\hline & Legalidad/Legal//legal & 1,29 & 0,06 \\
\hline & Familia & 0,93 & 0,61 \\
\hline \multirow[t]{6}{*}{ Neoliberalismo } & Burocracia & 0,21 & 0 \\
\hline & Emprendimiento & 2,32 & 0,86 \\
\hline & Responsabilidad & 0,36 & 0,15 \\
\hline & Competitividad & 0,10 & 0,07 \\
\hline & Sector privado & 0,43 & 0,83 \\
\hline & Comercio & 0,34 & 0,06 \\
\hline \multirow[t]{6}{*}{ Socialdemocracia } & Igualdad/Desigualdad & 0,13 & 1,14 \\
\hline & Equidad/Inequidad & 0,64 & 0,08 \\
\hline & Justicia social & 0,12 & 0,50 \\
\hline & \begin{tabular}{|l|} 
Trabajo \\
\end{tabular} & 0,33 & 1,64 \\
\hline & Solidaridad & 0,12 & 0,05 \\
\hline & Progreso & 0,12 & 0,03 \\
\hline
\end{tabular}

Fuente: elaboración propia.

${ }^{3}$ Aquí se excluyen tres usos de pueblo: a) cuando hace referencia a un municipio, por ejemplo, «Marinilla es un pueblo bello»; b) cuando hace referencia a la población de un municipio, por ejemplo, «el pueblo de Marinilla»; y c) cuando hace referencia a un pueblo extranjero, por ejemplo «el pueblo venezolano». En estos casos la palabra se utiliza para describir un territorio y su población, y no se articula como un sujeto político. 
De acuerdo a la tabla 2, en el discurso de Duque los conceptos centrales del conservadurismo y del neoliberalismo están más presentes que los del populismo y la socialdemocracia. Lo contrario sucede con los discursos de Petro, donde predominan los conceptos del populismo y la socialdemocracia.

Para resaltar mejor las diferencias ideológicas entre los dos candidatos se ha desarrollado un coeficiente ideológico, que es el promedio de las frecuencias de los diferentes conceptos dentro de cada ideología. Un coeficiente más grande implica una presencia más alta de la ideología respectiva (véase tabla 3 ).

Tabla 3. Coeficientes ideológicos en los discursos de Petro y Duque, 2017-2018.

\begin{tabular}{|l|c|c|c|c|}
\hline \multirow{2}{*}{ Discurso } & \multicolumn{4}{|c|}{ Ideología } \\
\cline { 2 - 5 } & Conservadurismo & Neoliberalismo & Populismo & Socialdemocracia \\
\hline Duque & 0,59 & 0,63 & 0,16 & 0,24 \\
\hline Petro & 0,16 & 0,33 & 0,70 & 0,57 \\
\hline Diferencia & 0,43 & 0,30 & 0,54 & 0,33 \\
\hline
\end{tabular}

[134] Fuente: elaboración propia.

La tabla 3 muestra claramente que tanto el conservadurismo como el neoliberalismo predominan en el discurso de Duque, mientras que el populismo y la socialdemocracia en el discurso de Petro. También revela que mientras Duque es más neoliberal que conservador, Petro es más populista que socialdemócrata. Finalmente, es interesante notar que el punto donde los dos discursos convergen más es en su dimensión neoliberal.

\section{La dimensión ideológica de los discursos anticorrupción de Duque y Petro}

Las ideologías de los dos candidatos presidenciales moldean su articulación de la corrupción. En el discurso de Duque la corrupción se articula principalmente como un problema del sector público (32\%), mientras que en el discurso de Petro se articula como un problema del sector público y del sistema socioeconómico en general (27\% y $26 \%$, respectivamente) (véase tabla 4). 
Neoconservadurismo versus populismo socialdemócrata. Una comparación...

Tabla 4. Articulación de la corrupción

en los discursos de Duque y Petro, 2017-2018.

\begin{tabular}{|l|c|c|}
\hline \multirow{2}{*}{ Categoría } & \multicolumn{2}{c|}{ Candidato } \\
\cline { 2 - 3 } & Duque & Petro \\
\hline Corrupción como fenómeno del sector público & $32 \%$ & $27 \%$ \\
\hline Corrupción como fenómeno del sector privado & $5 \%$ & $4 \%$ \\
\hline Corrupción público-privado & $14 \%$ & $14 \%$ \\
\hline Corrupción como fenómeno sociocultural & $14 \%$ & $26 \%$ \\
\hline Otros & $35 \%$ & $28 \%$ \\
\hline
\end{tabular}

Fuente: elaboración propia.

Tanto Petro como Duque ubican la corrupción principalmente en el sector público, sin embargo, esto no quiere decir que articulan la misma ideología. Primero, Petro enfatiza más la dimensión sociocultural de la corrupción como un fenómeno que caracteriza no solamente al sector público o privado, sino al sistema político, social y económico en general; segundo, en el discurso petrista la ubicación de la corrupción principalmente en el sector público está determinada por su ideología populista que lo relaciona con la clase política, los presidentes y las maquinarias políticas que pertenecen a la esfera pública, esto es, la articulación de la corrupción en el discurso de Petro se define principalmente por su tendencia populista más que por su postura socialdemócrata (véase tabla 5).

Tabla 5. Articulación populista de la corrupción en los discursos de Petro y Duque.

\begin{tabular}{|l|c|c|c|}
\hline Candidato & $\begin{array}{c}\text { Menciones de corrupción } \\
\text { analizadas }\end{array}$ & $\begin{array}{c}\text { Corrupción como característica } \\
\text { de la clase política }\end{array}$ & $\begin{array}{c}\text { Porcentaje } \\
\text { analizado }\end{array}$ \\
\hline Petro & 136 & 58 & 43 \\
\hline Duque & 123 & 0 & 0 \\
\hline
\end{tabular}

Fuente: construcción propia.

Como lo muestra la tabla 5, la ubicación de la corrupción en el sector público en el discurso de Petro está determinada por su ideología populista, la cual construye un pueblo honesto en antagonismo con una clase 
política corrupta. Petro califica a las élites colombianas como corruptas y sangrientas: «Tenemos una clase política degradada hundida absolutamente en la sangre y en la corrupción, por eso lo que tenemos es una degradación de la democracia» (Petro, 2018, mayo 5). En oposición a esta clase política, articula un pueblo honesto y digno que tenía «que irrumpir para restaurar moral y democráticamente la republica» (Petro, 2018, mayo 19). Para el candidato, la moralidad y la democracia están con el pueblo, la degradación y la dictadura con la clase política.

Los principales corruptos no son simplemente los caciques y gamonales locales, sino las élites políticas en Bogotá: «El corrupto no es Nule, ni es Ñoño [...] El corrupto es Santos, es Zuluaga, es Vargas Lleras, es Duque, y por encima de ellos, el capo Álvaro Uribe Vélez» (Yuri Lizarazo, 2018, marzo 30). Para Petro, se trata de una oligarquía que usa «el poder en su propio beneficio personal, en su propio beneficio patrimonial y no tienen ni idea en qué consiste el bien común, no tienen idea en qué consiste el interés general» (Carlos Alberto Ricchetti, 2018, mayo 10). La corrupción en Colombia es «el resultado que nos entrega una clase política tradicional que consideró que el poder era por herencia, que tenían derecho casi que divino a repartirse el poder sin tener en cuenta la decisión ciudadana» (Petro, 2018, mayo 4). Para mantenerse en el poder se había aliado con el narcotráfico, «se ha dejado comprar porque ella necesita para ser elegida comprar votos y compran los votos con los dineros del narcotráfico y de la corrupción» (Petro, 2018, mayo 13).

En el discurso petrista, la causa de la corrupción también es la estructura económica y social que la élite construyó. El sistema económico produce corrupción porque se basa en el latifundio feudal improductivo, en una economía extractiva de dinero fácil en lugar de una economía productiva erigida sobre le trabajo: «[...] la base de la corrupción hoy en Colombia está en el petróleo, está en el carbón y está en la cocaína, son los dineros fáciles [...] tiene una base esa cadena de corrupción, el robo de los recursos fáciles que ha generado el Estado colombiano el petróleo y el carbón» (Alex Band tercero, 2008, mayo 12). Se trata de un sistema económico que beneficia solamente a una minoría, puesto que se encuentra «arrodillado a cinco magnates» (Petro, 2018, junio 7). Acorde con Petro, los altos políticos colombianos, como Álvaro Uribe Vélez, «se arrodilla[n] ante el dueño del Banco de Bogotá» (Petro, 2018, mayo 13). 
Otra causa fundamental de la corrupción es «la desigualdad social, la que produjo en Colombia la corrupción» (Petro, 2018, mayo 5). La desigualdad es en parte producto del actuar de una élite corrupta que le ha quitado a la población la posibilidad de trabajar dignamente: «Nos han expropiado las condiciones del trabajo y por eso hay desigualdad social. Por eso hay injusticia social y por eso hemos tenido dos siglos de falta de democracia, de violencia y finalmente de narcotráfico, de corrupción» (Alex Band tercero, 2018, abril 4). Entonces, la raíz de la desigualdad se encuentra en la falta del trabajo digno. En este sentido, el trabajo es un concepto fundamental en la ideología petrista. Según el candidato, «lo único que puede enriquecer a una sociedad es el trabajo humano» (Petro, 2018, mayo 16). Por ello, en su plan de gobierno proponía «generar y mantener trabajo decente con condiciones dignas de remuneración [...]» (Petro, 2018, p. 11).

En resumen, en el discurso petrista la corrupción no caracteriza solamente a la clase política sino también al sistema sociopolítico y económico colombiano en general, donde falta trabajo digno, justica social, igualdad y participación popular en la política y la economía, mientras abunda el dinero fácil del narcotráfico y la extracción. Es un discurso que articula el concepto de la corrupción junto con conceptos clave del populismo y de la socialdemocracia, como clase política, trabajo, desigualdad y justicia social. En este sentido, la eliminación de la corrupción implica la eliminación de la clase política, la reducción de la desigualdad, la existencia del trabajo digno y de una economía productiva.

Según Petro, «la corrupción tiene detrás de sí una estructura económica y social que hay que cambiar si se quiere eliminar la corrupción» (R HG Colombia, 2018, abril 13). Por esta razón, su propuesta anticorrupción incluye cambios estructurales como la reforma agraria y la transformación del modelo económico. En palabras de Petro: «Un régimen de la corrupción se acaba, si se le entrega el poder constituyente a la gente para que decida sobre su territorio. Un régimen de corrupción termina si la sociedad es más igualitaria. Un régimen de corrupción termina si la economía es productiva» (Videos Varios, 2018, febrero 28).

A pesar de su dimensión izquierdista es importante resaltar que la propuesta de Petro no implica acabar con el capitalismo, al contrario, propone construir un verdadero capitalismo democrático en Colombia a 
través de «la democratización de la propiedad y del trabajo y del capital» (Petro, 2018, junio 7). El latifundio improductivo con su concentración de tierras en pocas manos es lo que obstaculiza el desarrollo del capitalismo moderno y mantiene a Colombia en la era feudal. Por este motivo, resulta «fundamental que el latifundio improductivo dejara de existir en Colombia porque a partir de la modernización agraria y no del feudalismo agrario se podría lograr la industrialización de obreros y empresarios» (Petro, 2018, abril 15). Petro plantea la democratización del capital para integrar en la economía de mercado a los estratos populares y los campesinos, multiplicando el número de los empresarios. "Queremos que haya dos millones, tres millones de empresarios» (Petro, 2018, junio 7), declara Petro en sus manifestaciones políticas.

Para Duque, por otro lado, la corrupción en su expresión más general representa una crisis de legalidad que se refleja desde la entrega del Estado a las FARC por el gobierno de Santos, hasta el robo de recursos públicos por los politiqueros y sus clientelas. Por esta razón, Duque declara que «el país está viviendo una crisis en materia de legalidad que empieza por la entrega que está haciendo el gobierno de las instituciones a las FARC [...]. Estamos viviendo una crisis en materia de legalidad, la corrupción administrativa campea en todas partes [...]» (Duque, 2017, noviembre 10).

La articulación de la corrupción con conceptos centrales del conservadurismo como la legalidad, produce una concepción del fenómeno como una crisis de legalidad, que a su vez requiere medidas duras para restaurar el orden y la legalidad. En este contexto, Duque propone penas más duras para los corruptos, «extinción de dominio exprés, cero casa por cárcel y cero reducción de penas, hasta el último día en cárceles con barrotes» (Centro Democrático, 2018, mayo 15).

Esta articulación conservadora de la corrupción se combina con una fuerte dimensión neoliberal que concibe la corrupción principalmente como el derroche del presupuesto público y, por lo tanto, lo ubica principalmente en la esfera pública y no en la privada. Según Duque, los colombianos están «cansados de la corrupción, cansados del derroche, cansados de que le pasen la cuenta con más impuestos a los ciudadanos» (Duque, 2017, abril 2). Entonces para eliminar la corrupción y librar a las empresas de los impuestos asfixiantes es esencial «una urgente revisión del gasto público para eliminar 
todo lo innecesario en el presupuesto de funcionamiento. Es fundamental un gobierno austero, que elimine el derroche y estimule la inversión» (Duque, 2018, marzo 24).

Desde la perspectiva neoliberal, la corrupción no consiste solamente en el derroche estatal sino también en la falta de competencia libre. Duque denuncia el hecho de que en el sector de la infraestructura o «en el régimen de regalías [...] el $80 \%$ de los recursos se queda en el $12 \%$ de los contratistas» (Duque, 2017, diciembre 23). Por lo tanto, una de sus medidas anticorrupción es "ponerle cerrojos a los abusos de contratación directa, que son los monopolios y la discrecionalidad» (Duque, 2017, diciembre 23). De la misma manera, denuncia la burocracia estatal colombiana que interfiere con el buen funcionamiento del mercado y del sector privado, alimentando la corrupción: «Las empresas en Colombia tienen que lidiar con múltiples diligencias frente una amplia cantidad de entidades que van desde la DIAN, la UGPP, el Invima, y hasta Sayco, [...] Estos costos encarecen el clima de negocios y alimenta la corrupción» (Duque, 2017, agosto 10). Aquí la corrupción se articula como la distorsión del funcionamiento del mercado y de la competencia libre por la interferencia estatal.

Naturalmente, Duque reconoce y denuncia la participación de actores y empresas privadas en actos de corrupción; sin embargo, no se trata de un reconocimiento de la corrupción en el sector privado per se, sino en la interacción entre el sector público y privado. Para acabar con la politiquería y el clientelismo propone, «declarar la muerte administrativa a firmas y gestores corruptos» (Duque, 2017, abril 20), la «empresa que compre funcionarios será ordenada su liquidación» (Duque, 2017, febrero 11). Defiende la eliminación de la contratación directa utilizada por los politiqueros para entregar el dinero público a los contratistas o actores privados que financian sus campañas electorales: «No podemos seguir permitiendo que la discrecionalidad entregue la contratación del Estado a quienes financian a los políticos o a quienes son representantes de los caciques» (Duque, 2017, febrero 11).

Como lo muestran las citas anteriores, los principales culpables de la corrupción en el discurso de Duque se encuentran en el sector público: los politiqueros que roban el erario, los gamonales, los caciques o los funcionarios públicos que ponen en las empresas públicas «gerentes para que les sirvan de administradores de la caja menor» (Tu opinión, 2018, 
mayo 30). Los corruptos son los gobernantes que utilizan la mermelada para comprar apoyo político en el Congreso, por lo cual, una de sus promesas electorales era: «se acaba la 'mermelada', y se acaba la entrega de entidades a las clientelas políticas en el país [...]» (Centro Democrático, 2018, mayo 30). Incluso fenómenos de la corrupción que pertenecen exclusivamente al sector privado, como la evasión fiscal, se articulan en el contexto de un Estado derrochador que ha fracasado en fiscalizar esta problemática, por lo cual, es fundamental «eliminar el derroche, que hagamos una reforma al Estado para que sea eficiente, que derrote la corrupción, que reduzca la evasión» (Duque, 2018, junio 9).

El sesgo ideológico neoliberal de Duque se manifiesta en la identificación de la corrupción del sistema de salud con los hospitales públicos y no con las EPS privadas (véase tabla 6).

Tabla 6. Salud y corrupción en el discurso de Duque, 2017-2018.

\begin{tabular}{|l|c|c|c|}
\hline \multicolumn{1}{|c|}{ Institución } & $\begin{array}{c}\text { Numero de } \\
\text { menciones }\end{array}$ & $\begin{array}{c}\text { Menciones en relación } \\
\text { con la corrupción }\end{array}$ & Porcentaje \\
\hline EPS & 27 & 0 & 0 \\
\hline Sistema de salud & 99 & 10 & 10 \\
\hline Hospitales (sistema/red hospitalaria) & 18 & 4 & 22 \\
\hline Hospitales públicos & 4 & 4 & 100 \\
\hline
\end{tabular}

Fuente: elaboración propia.

Naturalmente, Duque critica a las EPS de mala calidad y promete su cierre. También reconoce que las «EPS con mucha facilidad abusan de ciudadanos» (Duque, 2017, agosto 21). No obstante, nunca califica los abusos de las EPS privadas como corrupción, a pesar de que varios de los mayores escándalos del sistema de salud colombiano involucran actos de este tipo por dichas instituciones, como muestran los casos de Saludcoop y Cafesalud (Vega y Morales, 2016).

En resumen, la combinación de la corrupción con conceptos centrales conservadores como legalidad, y neoliberales como competencia, emprendimiento y mercado libre, produce una propuesta anticorrupción que se concentra en la reforma del Estado para recuperar su autoridad y fomentar la competencia y el emprendimiento libre. Para Duque, reformar el Estado 
y eliminar la corrupción son dos caras de la misma moneda, por eso afirma: "Vamos a hacerle una reforma al Estado. Vamos a luchar contra la corrupción» (Duque, 2018, marzo $1 .^{\circ}$ ). En este aspecto es muy diferente de la propuesta anticorrupción de Petro, que en lugar de una reforma administrativa del Estado propone un cambio en las estructuras políticas - eliminar la clase política tradicional-, sociales —más igualdad-y económicas —economía productiva- del país.

Para resumir de manera simplificada lo dicho anteriormente, se han organizado las diferencias y similitudes principales entre los discursos anticorrupción de Duque y Petro en el cuadro 2.

Cuadro 2. Discursos anticorrupción de Duque y Petro en la campaña presidencial de 2018.

\begin{tabular}{|l|l|l|}
\hline \multicolumn{1}{|c|}{ Discurso } & \multicolumn{1}{|c|}{ Duque } & \multicolumn{1}{|c|}{ Petro } \\
\hline Significante & Corrupción & Corrupción \\
\hline Significado & $\begin{array}{l}\text { Crisis de la legalidad } \\
\text { Derroche y robo de los recursos } \\
\text { públicos } \\
\text { Politiquería y clientelismo } \\
\text { Mermelada } \\
\text { Compra de los funcionarios } \\
\text { públicos por firmas privadas } \\
\text { Evasión fiscal } \\
\text { Contratación directa } \\
\text { Soborno, secuestro, extorsión, } \\
\text { violencia } \\
\text { Compra de votos }\end{array}$ & $\begin{array}{l}\text { Captura del Estado por la oligarquía } \\
\text { Ejercer poder en el interés privado y } \\
\text { no en el interés general } \\
\text { Degradación de la clase política } \\
\text { Clientelismo y maquinarias políticas } \\
\text { Delitos contra lo público } \\
\text { Compra de votos } \\
\text { Soborno }\end{array}$ \\
\hline $\begin{array}{l}\text { Ubicación de } \\
\text { la corrupción }\end{array}$ & $\begin{array}{l}\text { Sector público } \\
\text { Sector público-privado: actores } \\
\text { privados que corrompen } \\
\text { funcionarios públicos } \\
\text { Caciques, gamonales, politiqueros } \\
\text { Funcionarios públicos }\end{array}$ & $\begin{array}{l}\text { La alta clase política colombiana } \\
\text { (Santos, Uribe, Vargas Lleras y } \\
\text { Duque) } \\
\text { El sistema económico, político y } \\
\text { social de Colombia } \\
\text { El sector público }\end{array}$ \\
\hline $\begin{array}{l}\text { Causas de la } \\
\text { corrupción }\end{array}$ & $\begin{array}{l}\text { Politiquería y clientelismo } \\
\text { El derroche e ineficiencia del } \\
\text { Estado } \\
\text { Empresas privadas que sobornan } \\
\text { funcionarios públicos } \\
\text { Actores privados que hacen } \\
\text { evasión fiscal }\end{array}$ & $\begin{array}{l}\text { La clase política tradicional } \\
\text { La desigualdad social } \\
\text { El modelo económico extractivo } \\
\text { que se basa en el «dinero fácil» de } \\
\text { petróleo, carbón } \\
\text { La alianza entre la clase política y el } \\
\text { narcotráfico } \\
\text { Estructuras económicas y sociales de } \\
\text { Colombia }\end{array}$ \\
\hline
\end{tabular}




\begin{tabular}{|l|l|l|}
\hline Propuesta & Fortalecer la legalidad & Cambiar la clase política tradicional \\
anticorrupción & Eliminar el derroche del erario & de Colombia \\
& Endurecer penas para los corruptos & Cambiar el sistema económico: \\
& Desregularización y reducción de & desde la economía extractiva hacia la \\
& tramites & economía productiva \\
& Eliminar la contratación directa & Democratizar la política: gobierno \\
& Eliminar la mermelada & del pueblo no de las élites \\
& Eliminar la politiquería y el & Reducir la desigualdad \\
& clientelismo & Ampliar la educación publica \\
& Extinción de dominio exprés & \\
\hline
\end{tabular}

Fuente: elaboración propia.

En este punto es importante resaltar que los discursos anticorrupción no solamente reflejan sus respectivas ideologías, sino que sirven también para construirlas. Esto resulta particularmente claro en el discurso de Duque, donde el significante «anticorrupción» empieza a funcionar como un significante vacío que adquiere tantos significados que casi pierde un significado particular $y$, por lo tanto, une varias demandas, a veces contradictorias. En su caso, la anticorrupción implica restaurar la legalidad, un Estado austero que evite el derroche, más inversión pública, estimular la competencia, subir los salarios, reducir los impuestos, incentivar la inversión, el emprendimiento y también reducir la desigualdad (véase gráfica 1).

El significante anticorrupción sirve para unir demandas que podrían ser contradictorias, por ejemplo, menos impuestos, Estado austero, demandas para mayor gasto público en salud o educación, y reducción de la desigualdad. Normalmente estas demandas serían contradictorias, empero, a través de la anticorrupción se pueden presentar como equivalentes. Reducir el derroche del erario constituiría más dinero público, más inversión pública, por lo tanto, menos desigualdad y la posibilidad de bajar «impuestos y a subir los salarios de los trabajadores colombianos» (Duque, 2018, junio 14). Obviamente, esta lógica supone que el problema principal en Colombia es el derroche del erario y no la inversión insuficiente en sectores como la educación pública, por ejemplo, o la captura del Estado por actores privados. 
Gráfica 1. Anticorrupción como significante vacío en el discurso de Duque.

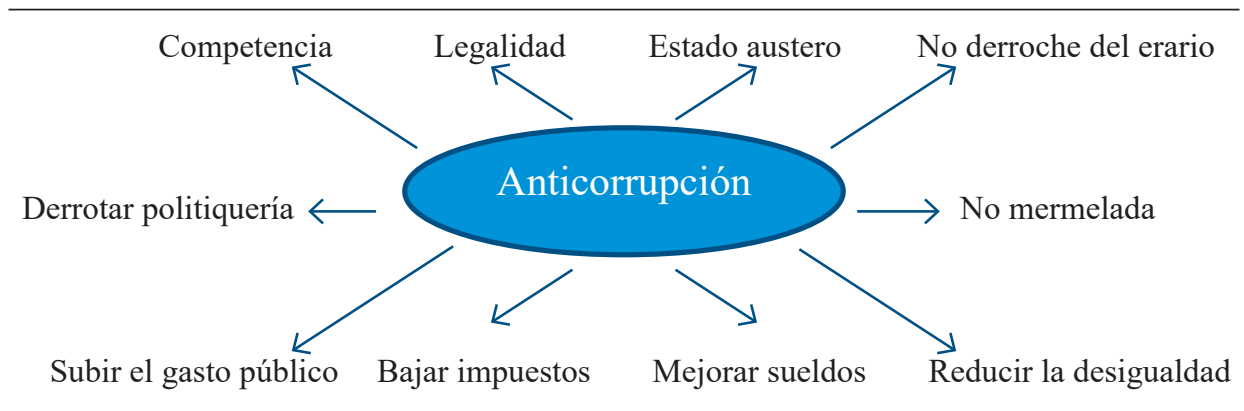

Fuente: elaboración propia.

\section{Conclusión: hacia un análisis ideológico de los discursos anticorrupción}

En este artículo se ha mostrado que los discursos de los candidatos presidenciales Gustavo Petro e Iván Duque, a pesar de sus similitudes, producen dos propuestas anticorrupción distintas. Para Duque la anticorrupción es sinónimo de reformar el Estado para eliminar el derroche del erario, mejorar la contratación pública o introducir penas más duras contra los corruptos. Por otro lado, en el discurso petrista la anticorrupción entraña transformaciones más profundas en el sistema político, económico y social, desde el cambio de la clase política tradicional hasta la transformación del modelo económico.

Este contraste resulta de la diferenciación ideológica entre los dos candidatos: Duque articula una propuesta neoconservadora que combina el enfoque conservador de mantener el statu quo con conceptos básicos de la ideología neoliberal, como la competencia y el mercado libre como fuentes principales del desarrollo socioeconómico. En consecuencia, identifica la corrupción con la crisis de legalidad, también la ubica principalmente en el sector público y su propuesta anticorrupción se limita a la reforma del Estado y no de las estructuras socioeconómicas del país. Asimismo, el discurso anticorrupción de Petro se puede entender solamente dentro de su populismo socialdemócrata que combina el antagonismo pueblo-élite con conceptos centrales de la socialdemocracia como la justicia social, el progreso, la igualdad y el trabajo como valores fundamentales. Por esta razón, asocia 
la corrupción con la degradación de la clase política y del sistema político, económico y social que esta había construido, y su propuesta anticorrupción conlleva una transformación estructural del orden vigente.

En este orden de ideas, es importante desenterrar la dimensión ideológica de una propuesta anticorrupción. Primero, es necesario identificar los ideales o supuestos políticos sobre los cuales se erige la misma, resulta conveniente preguntar cuál es el ideal político, económico o social que se pretende establecer a través de la eliminación de la corrupción; segundo, es importante evaluar si el discurso anticorrupción sirve para esconder o exponer este ideal político, económico o social, cualquier discurso que pretende articular la corrupción como un hecho simplemente empírico ignora su dimensión ideológica y, por esta razón, tiende a asfixiar el debate político sobre este.

Infortunadamente, esta concepción fundamenta la lucha anticorrupción en la mayoría de los casos. Es una lucha que, como tantas otras - contra las drogas o el terrorismo-, se enfoca en las consecuencias para desviar la atención de las causas que engendran los mismos fenómenos que se combaten. La presentación de la corrupción como un enemigo que hace

[144] estragos en la sociedad y, por eso, hay que derrotarlo, crea la ilusión de un sujeto autónomo que esconde su dimensión ideológica y lo transforma de una consecuencia a la causa de la degradación del orden político. En este contexto, la lucha anticorrupción puede fácilmente servir para desviar el debate político desde la evaluación de la justicia, funcionamiento o legitimidad de un orden político hacia su mantenimiento.

\section{Referencias bibliográficas}

1. Alex Band tercero. (2008, mayo 12). Gustavo Petro en Armenia [Archivo de video]. Recuperado de https://www.youtube.com/watch?v=_gmpxk-_ 40

2. Alex Band tercero. (2018, abril 4). Petro en Magangué, Bolívar [Archivo de video]. Recuperado de https://www.youtube.com/watch? $v=$ CEZwbNK1i1c

3. Carlos Alberto Ricchetti. (2018, mayo 10). Discurso completo de Gustavo Petro en la Plaza Bolívar de Pereira [Archivo de video]. Recuperado de https://www. youtube.com/watch? $\mathrm{v}=\mathrm{CFB}-\mathrm{vwc0uT0}$

4. Centro Democrático. (2018, mayo 15). Necesitamos acabar con la exclusión regional: Iván Duque. Recuperado de https://www.centrodemocratico. $\mathrm{com} / ? \mathrm{p}=1334 \#$.XSe14-hKiM8 
5. Centro Democrático. (2018, mayo 30). No tengo compromisos burocráticos con nadie: Duque. Recuperado de https://www.centrodemocratico.com/?p=1541\#. XSe0ZOhKiM8

6. Duque, Iván. (2017, febrero 11). ¡Sí podemos combatir la corrupción! Recuperado de http://www.ivanduque.com/comunicados/217/Si-podemos-combatirla-corrupcion

7. Duque, Iván. (2017, abril 2). No permitiremos que le entreguen las instituciones al terrorismo: Iván Duque. Recuperado de http://www.ivanduque.com/ comunicados/208/No-permitiremos-que-le-entreguen-las-instituciones-al-terrorismo-Ivan-Duque

8. Duque, Iván. (2017, abril 20). Desde la cabeza del Estado vamos a combatir la corrupción. Recuperado de http://www.ivanduque.com/comunicados/203/Desde-lacabeza-del-Estado-vamos-a-combatir-la-corrupcion

9. Duque, Iván. (2017, agosto 10). Para que un país prospere necesita un sector privado pujante: Iván Duque. Recuperado de http://www.ivanduque.com/ comunicados/173/Para-que-un-pais-prospere-necesita-un-sector-privado-pujante-Ivan-Duque-

10. Duque, Iván. (2017, agosto 21). El próximo gobierno, que será del Centro Democrático, le va a cerrar las válvulas al derroche: Iván Duque. Recuperado de http://www.ivanduque.com/comunicados/167/El-proximo-gobierno-que-sera-delCentro-Democratico-le-va-a-cerrar-las-valvulas-al-derroche--Ivan-Duq...

11. Duque, Iván. (2017, noviembre 10). Queremos conquistar la legalidad: Iván Duque, Tolima, Colombia, 10 de noviembre de 2017. Recuperado de http://www. ivanduque.com/comunicados/139/Queremos-conquistar-la-legalidad--Ivan-Duque-

12. Duque, Iván. (2017, diciembre 23). Tenemos que ponerle cerrojos a los abusos de la contratación directa, dijo Duque en Cumbre Internacional. Recuperado de https://www.ivanduque.com/comunicados/212/Tenemos-que-ponerle-cerrojos-alos-abusos-de-la-contratacion-directa-dijo-Duque-en-Cumbre-Internacional

13. Duque, Iván. (2018, marzo 1.º). Discurso Duque en Montería [Archivo de vídeo]. Montería, Colombia, 1 de marzo de 2018. Recuperado de https://www. youtube.com/watch?v= jeiv927CihM

14. Duque, Iván. (2018, marzo 24). Culmina agenda de trabajo en Estados Unidos del candidato presidencial Iván Duque y su fórmula Marta Lucía Ramírez. Recuperado de http://www.ivanduque.com/comunicados/80/culmina-agenda-de-trabajo-enestados-unidos-del-candidato-presidencial-ivan-duque-y-su-formula-marta-...

15. Duque, Iván. (2018, junio 9). Iván Duque presentó sus propuestas sociales en Cundinamarca. Duque FM. Recuperado de https://www.duque.fm/noticias/ivanduque-en-cundinamarca/

16. Duque, Iván. (2018, junio 14). Duque se comprometió con la creación del Fondo de Estabilización de Precios del Café. Duque FM. Recuperado de http://www. duque.fm/noticias/duque-creacion-del-fondo-de-estabilizacion-de-precios-del-cafe/ 
17. Foucault, Michel. (2007). Nacimiento de la biopolítica. Bogotá, D. C.: Fondo de Cultura Económica.

18. Freeden, Michael. (1996). Ideologies and Political Theories: A Conceptual Approach. Oxford: Clarendon.

19. Freeden, Michael. (2013). Ideología: una breve introducción. Santander: Universidad de Cantabria.

20. Harvey, David. (2007). Breve historia del neoliberalismo. Madrid: Akal.

Heywood, Andrew. (2017). Political Ideologies: An Introduction. London: Palgrave. DOI: 10.1057/978-1-137-60604-4

21. Howarth, David. (2000). Discourse. Buckingham: Open University.

22. Huntington, Samuel. (1957). Conservatism as an Ideology. The American Political Science Review, 51 (2), pp. 454-473. DOI: 10.2307/1952202

23. Kajsiu, Blendi. (2017). Una teoría socio-morfológica del populismo: el caso del uribismo (2002-2010). Análisis Político, 90, pp. 209-225. DOI: 10.15446/anpol. v30n90.68561

24. Kajsiu, Blendi. (2018). The Ideological Malleability of Corruption. A Comparative Analysis of Official Corruption Discourses in Albania and Colombia, 2010-2017. Südosteuropa, 66 (3), pp. 299-324. DOI: 10.1515/soeu-2018-0026

25. Laclau, Ernesto \& Mouffe, Chantal. (1984). Hegemony and Socialist Strategy: Towards a Radical Democratic Politics. London: Verso.

26. Laclau, Ernesto. (2005). Populism: What's in a Name? In: Panizza, Francisco

[146] (ed.). Populism and the Mirror of Democracy. (pp. 32-50). London: Verso.

27. Laval, Christian y Dardot, Pierre. (2010). La nueva razón del mundo. Ensayo sobre la sociedad neoliberal. Barcelona: Gedisa.

28. Montoya, Mario. (2000). La instrumentación política de la corrupción. Estudios Políticos, 16, pp. 103-117.

29. Petro, Gustavo. (2018). Colombia Humana hacia una era de paz. Programa de gobierno del candidato presidencial Gustavo Francisco Petro Urrego para el período 2018-2022. La Silla Vacía. Recuperado de https://lasillavacia.com/sites/default/files/ programa_colombia_humana_-_documento_politica_agraria_final_0.pdf

30. Petro, Gustavo. (2018, abril 15). Gustavo Petro en discurso desde Sogamoso [Archivo de vídeo]. Recuperado de https://www.youtube.com/ watch?v $=7 \mathrm{ANSpGdbDdQ}$

31. Petro, Gustavo. (2018, mayo 4). Gustavo Petro en Neiva Huila 04/05/2018 [Archivo de vídeo]. Neiva, Colombia, 4 de mayo de 2018. Recuperado de https:// www.youtube.com/watch?v=eBZP1_Ms7GU

32. Petro, Gustavo. (2018, mayo 5). Gustavo Petro en Mocoa 05/05/2018 [Archivo de vídeo]. Recuperado de https://www.youtube.com/watch?v=gWX_cwAaeCs

33. Petro, Gustavo. (2018, mayo 13). Gustavo Petro en Cartago Valle del Cauca - Manifestación Colombia Humana [Archivo de Vídeo]. Recuperado de https://www. youtube.com/watch? $v=8 b P 1$ LyxfTDU 
34. Petro, Gustavo. (2018j, mayo 16). Cierre de campaña del candidato presidencial Gustavo Petro en Medellín, Antioquia - mayo 16 de 2018 [Archivo de vídeo]. Recuperado de https://www.youtube.com/watch?v=_gD-MOSnY5c

35. Petro, Gustavo. (2018, mayo 19). Gustavo Petro en cierre de campaña en Cali [Archivo de vídeo]. Recuperado de https://www.youtube.com/ watch? $\mathrm{v}=$ ZGagVHoCvAk

36. Petro, Gustavo. (2018, junio 7). Entrevista de Gustavo Petro en Radio Nacional de Colombia - Duque, Fraude electoral y propuestas [Archivo de vídeo]. Recuperado de https://www.youtube.com/watch?v=eXbFhljjtb4

37. Philp, Mark \& David-Barret, Elizabeth. (2015). Realism about Political Corruption. Annual Review of Political Science, 18, pp. 387-402. DOI: 10.1146/ annurev-polisci-092012-134421

38. Philp, Mark. (1997). Defining Political Corruption. Political Studies, 45 (3), pp. 436-462. DOI: 10.1111/1467-9248.00090

39. R HG Colombia. (2018, abril 13). Gustavo Petro en Ibagué [Archivo de video]. Recuperado de https://www.youtube.com/watch?v=bAh5F_lh-ZM

40. Stanley, Ben. (2008). The Thin Ideology of Populism. Journal of Political Ideologies, 13 (1), pp. 95-110. DOI: 10.1080/13569310701822289

41. Torfing, Jacob. (2004). New Theories of Discourse: Laclau, Mouffe and Zizek. Oxford \& Massachusetts: Blackwell.

42. Tu opinión-todo es noticia. (2018, mayo 30). ¡Exclusiva! entrevista de Iván Duque en La W. 30/05/2018 [Archivo de video]. Recuperado de https://www.youtube. com/watch?v=3CRPqaUL2Tw

43. Vásquez, Ana Victoria y Montoya, Mario. (2011). Corrupción, lucha anticorrupción y formas de gobierno. Estudios de Derecho, 68 (152), pp. 229-253.

44. Vega, Camilo y Morales, Felipe. (2016, 5 de marzo). Cafesalud, en cuidados intensivos por corrupción. El Espectador. Recuperado de https://www.elespectador. com/noticias/nacional/cafesalud-cuidados-intensivos-corrupcion-articulo-620482

45. Videos Varios. (2018, febrero 28). Gustavo Petro en Cali lleno total [Archivo de video]. Recuperado de https://www.youtube.com/watch?v=e5QTgc1fDyg

46. Yuri Lizarazo. (2018, marzo 30). Gustavo PetrodesdeSahagún Córdoba[Archivo de video]. Recuperado de https://www.youtube.com/watch? $v=y w x B o v n D 1 H Q$ 